\title{
Synthesis and Characterization of Biodiesel from Khaya senegalensis Seed Oil using Heterogeneous Catalyst
}

Mohammed Babakura $^{{ }^{1}}$, Jibrin M. Yelwa* ${ }^{2}$, Abubakar Ibrahim ${ }^{3}$, Bashir M. Aliyu ${ }^{4}$, Jibrin Y. Yahaya ${ }^{5}$, Jamilu B. Umar ${ }^{6}$, Musa M. Auwal ${ }^{7}$ and Alexender O. Ogabidu ${ }^{8}$

1,2,3,4,5,6,7,8 Department of Scientific and Industrial Research, National Research Institute for Chemical Technology, Zaria, PMB 1052, Nigeria.

\begin{abstract}
Biodiesel was produced by transesterifying Khaya senegalensis oil with methanol in the presence of $\mathrm{Al}_{2} \mathrm{O}_{3}$ as catalyst. Molar ratio of 15:1 (methanol to oil) was followed to shift the reaction to product side for more yield of fatty acid methyl esters (FAME) and the use of a heterogeneous catalyst enabled the reaction to proceed faster. The oil and biodiesel were characterized following ASTM standards. The free fatty acid, acid value, viscosity, specific gravity, moisture content, saponification value, pour point, cloud point were examined in this research and the result obtained show that Khaya senegalensis Seed Oil is a good for biodiesel production. The biodiesel obtained was separated from glycerol, washed with distilled water and dried. Samples of oil and biodiesel were scan within mid-infrared region of $4000 \mathrm{~cm}^{-}{ }^{1}-400 \mathrm{~cm}^{-}{ }^{1}$ with fourier transform infrared spectrometer by agilent technologies. The spectra obtained were interpreted and analyzed with the aid of structure correlation chart. The results revealed that the biodiesel contained fatty acid methyl esters (FAME). The FTIR spectrum for the biodiesel revealed the functional groups with characteristics bands, $\mathrm{C}=\mathrm{O}$, $-(\mathrm{CH} 2) n$-, $C-O, C=C$ and $C-H$ in the spectrum.
\end{abstract}

Keywords - Biodiesel, Khaya senegalensis Seed Oil, FTIR, Heterogeneous Catalyst, Tranesterification.

\subsection{INTRODUCTION}

The price of petroleum has risen as a result of depletion of fossil fuels and the pollution caused by vehicles is of environmental concern. This necessitated the need for alternative energy like biodiesel. Biodiesel is biodegradable, non-harmful and renewable, Edeh and Yelwa, (2019). Biodiesel is an alternative fuel made from renewable biological sources such as fats and oil (whether edible or non-edible oil). Vegetable oils are usually esters of glycol with different chain length and degree of saturation (Antony Raja et al., 2011). Significant attention is given to biodiesel because of environmental concern and the prediction that conventional fuel may become scarce in the new future, Edeh and Yelwa, (2019). Biodiesel is a renewable, green alternative fuel that can be manufactured from vegetable oils, animal fats or recycled greases. With the increase of petroleum price and the environmental concerns about pollution, it has become the most potential biofuel because of many advantages such as its environmental friendliness and its better efficiency than fossil fuel (Demirbas, 2007). Synthesis of biodiesel is done by reacting the vegetable oil with suitable alcohol (esterification or transesterification). Methanol or ethanol are usually the alcohol for biodiesel preparation. Suitable catalyst, heterogeneous or homogeneous, may be use to speed up the reaction. The amount of free fatty acid is import in order to select the appropriate catalyst (Helwani et al., 2009). In the present paper, we adopt the most mature and wildly-used method in biodiesel production, i.e. using a heterogeneous basic catalyst Edeh and Yelwa (2007). Several plant species are presently use in the production of biodiesel, among which is Khaya senegalensis. Khaya senegalensis is a large tree native to the sub-sahara savannah from Senegal to Uganda and is used in traditional medicine in Africa. Instrumental analyses are carried out to analyze the biodiesel products and seed oils in detail.

\subsection{Sample preparation}

\subsection{METHODOLOGY}

Dry and mature Khaya senegalensis seed was collected from NARICT Staff quarters Zaria, Kaduna State. Nigeria. The seed was removed. The oil was extracted using maceration method using petroleum ether as 
solvent. The \% yield was calculated to know the yield. The selection of the alkanol for transesterification reaction was strictly based on cost. Hence, methanol was use for this work. Based on availability, cost and performance, $\mathrm{Al}_{2} \mathrm{O}_{3}$ was use as a catalyst in the reaction.

\subsection{Transesterification Procedure}

The method illustrated by Taufiq-Yap et at (2010) and Veljkovic et al. 2006 was adopted for the production of biodiesel from non-edited vegetable oil of Khaya senegalensis seed. The uniqueness of this investigation was the homogeneous system that was created to investigate the production of biodiesel. It involved the use of heterogeneous base catalysts $\mathrm{Al}_{2} \mathrm{O}_{3}$. Biodiesel production was carried out in at two-neck round-bottom flask reactor equipped with a reflux condenser stirrer. The reaction flask was immersed in a glass chamber placed on the plate of a magnetic stirrer $(800 \mathrm{rpm})$. The temperature was maintained at $60^{\circ} \mathrm{C}$ by water circulating from a thermostat pump. Typically, $\mathrm{Al}_{2} \mathrm{O}_{3}(5 \mathrm{wt} \%)$ was suspended in a required volume of methanol. Consequently, oil was varied into the mixture under vigorous stiring. The methanol/oil molar ratio was 15:1 at the end of reaction (5hrs), the catalyst was separated via centrifugation and the reaction mixture was then loaded into a rotary evaporated to remove excess methanol. Conversion of Khaya senegalensis seed oil to biodiesel by $\mathrm{Al}_{2} \mathrm{O}_{3}$ was compared. Since the transesterification of triglycerides can produce methyl ester (biodiesel) and by product glycerol, the conversion of oil was calculation based on the amount of recovered methyl ester (biodiesel).

\subsection{Catalyst Dosage}

The investigation was carry out using $5 \%$ of the catalyst and observe the corresponding yield of methyl ester at a temperature of $60^{\circ} \mathrm{C}$ for 5 hours with methanol to oil ratio of $15: 1$ and $800 \mathrm{rpm}$.

\subsection{Oil Characterization}

\subsubsection{Determination of Free Fatty Acid ( F F A)}

Determination of Free Patty Acid is based on (AOAC, I998). $0.5 \mathrm{~g}$ of sample oil was boiled with $5 \mathrm{~cm}^{3}$ of ethanol and was allowed to cool. 2 drops of phenolphthalein indicator were added and titrated with $0.1 \mathrm{M} \mathrm{NaOH}$ until pink color disappears; free fatty acid was calculated using the expression below:

$\mathrm{FFA}=\frac{\mathrm{V} \times \mathrm{Na} \times \mathrm{F} \times 100}{\text { Weight of sample }}$

Where, $\mathrm{V}=$ Volume of sodium hydroxide, $\mathrm{Na}=$ normality of sodium hydroxide. $\mathrm{F}=$ Equivalent factor,

\subsubsection{Determination Acid Value}

Determination of Acid Value was done according to (AOAC, 1990). The acid value of the sample oil was determined by dissolving about $5.0 \mathrm{~g}$ of the sample oil in a hot mixture of $25 \mathrm{ml}$ diethyl ether and $25 \mathrm{ml} \mathrm{95 \%} \mathrm{v/v} \mathrm{ethyl} \mathrm{alcohol.} \mathrm{The} \mathrm{hot} \mathrm{solution} \mathrm{was} \mathrm{neutralized} \mathrm{with} 0.1 \mathrm{M} \mathrm{NaOH} \mathrm{using}$ phenolphthalein as indicator. The acid value was then determined using the equation below.

$$
\mathrm{Av}=\quad \frac{\mathrm{M} \times \mathrm{C} \times \mathrm{TV}}{\mathrm{W}}
$$

Where $\mathrm{M}=$ molar mass of $\mathrm{KOH}(56.1), \mathrm{C}=$ concentration of $\mathrm{KOH}(0.1 \mathrm{M})$. Tv = volume of $\mathrm{NaOH}, \mathrm{w}=$ the weight, in $\mathrm{g}$, of the oil.

\subsubsection{Specific Gravity Determination}

Specific gravity was determined according to the standard method contained in ASTM D5002 (ASTM, 1998). The sample oil was poured into a vertical glass cylinder and a hydrometer was placed in the oil and allowed to be stable, the value of the specific gravity was taken from the marking on the stem of the hydrometer at the surface of the oil.

\subsubsection{Determination of Moisture Content}

The ground seed $(2 \mathrm{~g})$ will be placed in a dried and weighed crucible. The crucible with the ground seed was placed in the Griffin temperature adjustable oven at $110^{\circ} \mathrm{C}$. Heating and weighing were carried out at intervals of 1 (one) hour until a constant weight was obtained. The crucible was allowed to cool, the weight and percentage (\%) moisture content was calculated, Danbature et al. (2013). 


\subsubsection{Determination of Saponification value}

The method described by Nkafamiya et al. (2007). Was adopted oil sample (2 g) was added to $0.1 \mathrm{M}$ alcoholic $\mathrm{KOH}$. The resulting solution was heated to $60^{\circ} \mathrm{C}$ with constant stirring for 5 minutes for the oil to Saponify. The unreacted $\mathrm{KOH}$ was titrated with $0.5 \mathrm{M} \mathrm{HCl}$ using phenolphthalein as indicator, until the solution turned pink. The process was repeated two more times and the average titre value was calculated. The saponification value (SV) was calculated as follows:

$\mathrm{SV}=\underline{(\mathrm{B}-\mathrm{S}) * \mathrm{M} * 56.1}$

Wt of sample

Where $\mathrm{B}=$ blank titre

$\mathrm{S}=$ Sample titre volume

$\mathrm{M}=$ Concentration of $\mathrm{HCl}(0.5 \mathrm{M})$

\subsection{Biodiesel Characterization}

\subsubsection{Determination of Viscosity}

The viscosity was determined by the Cannon-Fenske viscometer and a circulatory bath with temperature control. Viscosity was calculated using ASTM method D445-97(ASTM, 1997). The viscometer was washed and dried. The sample was sucked into it and was immersed into a circulatory bath set at $30^{\circ} \mathrm{C}$. The time of flow of sample from upper mark to lower mark of the viscometer was recorded using a stop watch. The experiment was repeated thrice and the average flow time was recorded. This will be carried out on oil before and after transesterification. The instrumental constant was obtained from the viscometer thus viscosity of the sample was calculated using the formula below: Viscosity $(\mathrm{V})=\mathrm{KT}$,

Where $\mathrm{K}=$ instrumental constant. $\mathrm{D}$ = density of the sample, $\mathrm{T}=$ efflux time (s)

\subsubsection{Determination of Cloud point}

For the Determination of Cloud point, method of Danbature et al. (2015) was adopted. A Biodiesel Sample $\left(20 \mathrm{~cm}^{3}\right)$ was poured into a test tube and held vertically in a beaker containing ice and sodium chloride. The temperature at which cloud appear was recorded as the cloud point. The development was frequent three times and the average was planned.

\subsubsection{Determination of pour point}

For the Determination of Cloud point, method of Danbature et al. (2015). Was adopted A Biodiesel Sample $\left(20 \mathrm{~cm}^{3}\right)$ allowed to super cool in a deep freezer (reading up to $-20^{\circ} \mathrm{C}$ ). they were the removed and placed in test tube racket under room temperature. The temperature at which sample began to melt is recorded as the pour point. Three determinations were obtained and average calculated.

\subsubsection{Determination of Flash Point}

The flash point is ability of a sample to produce an inflammable mixture with an ignition source. $15 \mathrm{ml}$ of the biodiesel poured into a $250 \mathrm{ml}$ conical flask was heated and passed over the surface of the liquid. The temperature, at which the vapour ignited, was recorded as the flash point temperature. Three determinations were obtained and average calculated. (Edeh and Yelwa, 2019)

\subsection{Characterization of Khaya senegalensis seed oil and its biodiesel using Fourier Transform Infrared Spectrometer (FTIR) technique.}

Structural property of oil and the biodiesel were characterized using Fourier Transform Infrared Spectroscopy (FTIR). The FT-IR spectra were recorded on KBr discs in the wavenumber range of 500 to 4000 cm-1 on Buck scientific infrared spectrophotometer, Model 530. 


\subsection{RESULT AND DISCUSSION}

\subsection{FTIR}

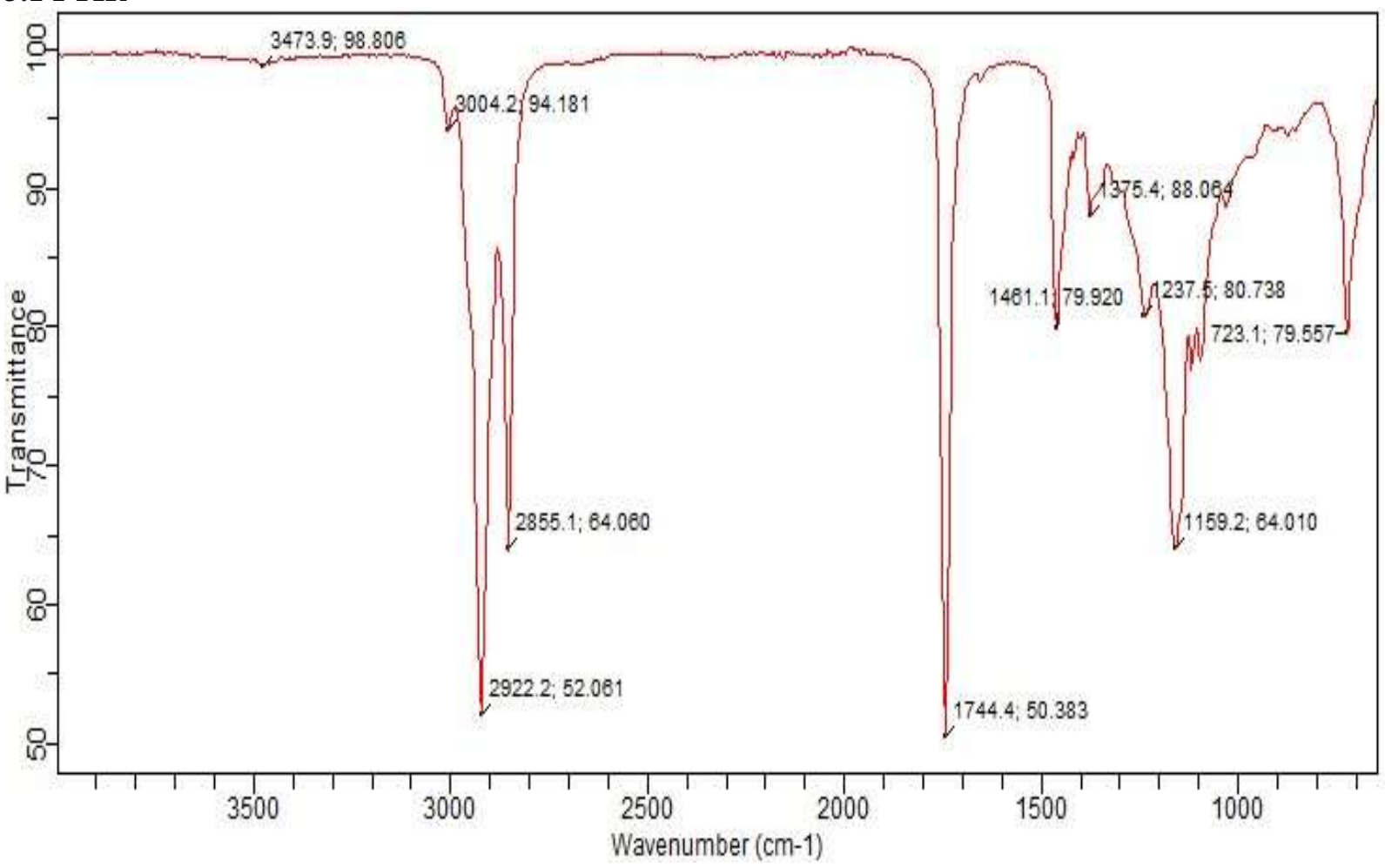

Figure 1. FTIR spectrum of the Khaya senegalensis seed oil

The FTIR spectroscopy is a rapid, non-destructive technique that has been widely applied in the characterization of lipids because lipids have functional groups with characteristic absorption bands in the infrared region of the electromagnetic spectrum Yelwa et al, (2019). Figure 1 shows the FTIR spectrum of Khaya senegalensis seed oil. Different intense peaks such as the doublet of the $-\mathrm{CH}_{3}$ and $-\mathrm{CH}_{2}$ anti-symmetric stretching vibration at $2922.2 \mathrm{~cm}^{-1}$ and $2855.1 \mathrm{~cm}^{-1}$ were also detected. Another peak at $1744.4 \mathrm{~cm}^{-1}$ was observed, which can be attributed to the stretching of $\mathrm{C}=\mathrm{O}$, typical of esters, and thus are common in both FAME and refined oil spectra, Soares et al. (2008). The peak at 1461.1 $\mathrm{cm}^{-1}$ correspond to the asymmetric stretching of $\mathrm{CH}_{3}$ present in the refined oil spectrum, Soares et al. (2008). The peak at $1374 \mathrm{~cm}^{-1}$ can be attributed to the glycerol group O-CH2 (mono-, di- and triglycerides), which is present in the refined oil spectrum. The stretching of $\mathrm{O}-\mathrm{CH}_{3}$, represented by the absorbance at $1156 \mathrm{~cm}^{-1}$. The specific peak at $721.4 \mathrm{~cm}^{-1}$ indicate methylene functional group in the biodiesel (-( $\left.\left.\mathrm{CH}_{2}\right) \mathrm{n}-\right)$.

Table 1: Oil Quality Parameter of Khaya senegalensis seed oil

\begin{tabular}{cc}
\hline Parameter & Khaya senegalensis seed oil \\
\hline \% yield & 66.300 \\
Saponification value & 296.800 \\
Acid Value & 0.140 \\
Specific gravity & 0.916 \\
Moisture content & 22.297 \\
Free Patty Acid & 0.071 \\
\hline
\end{tabular}

The oil yield of $66.30 \%$ of the Khaya senegalensis (Table 1) is higher than that obtained by Danbature et al. (2015). The oil yield of Khaya senegalensis is higher than that of soy bean (15-21\%) and rape seed (>40\%) (Okieimen and Eromosele, 1999) and lower than that of sunflower seed oil (78\%) Yelwa et al. (2017). This value is considered as reasonable recovery yield. According to Jibrail and Kaet (2013), a crop that produces high amount of oil is desirable for biodiesel production as it could be used as a feasible alternative. The improvement in the oil recovery of Khaya senegalensis seed oil could be attributed to the modified method of extraction. The 
acid value of Khaya senegalensis seed oil $(0.140 \mathrm{mgKOH} / \mathrm{g})$ is same as $1.14 \mathrm{mgKOH} / \mathrm{g}$ reported by Danbature et al., 2015 but lower than $0.15 \mathrm{mgKOH} / \mathrm{g}$ reported by Yelwa et al., (2017). This may be attributed to the new improved method of extraction. The low acid value demonstrates the feasibility of alkali - catalyzed transesterification Danbature et al. (2015).

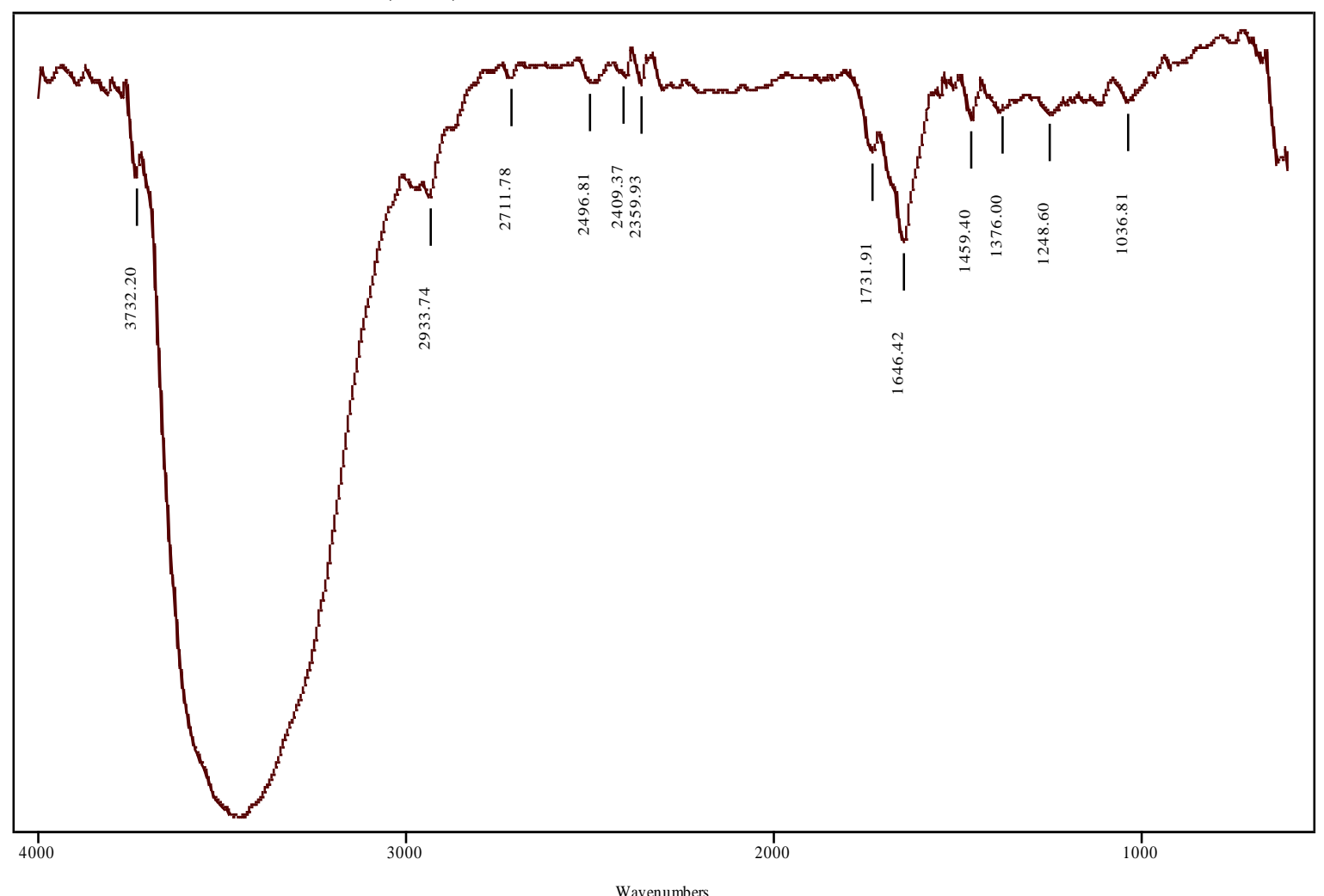

Figure 2. FTIR spectrum of the biodiesel

Figure 2 shows the FTIR of the synthesized biodiesel. The peak at $3500 \mathrm{~cm}^{-1}$ with stretching mode of vibration is ascribed to the presence of $\mathrm{O}-\mathrm{H}$ groups. They are single bounded and at high energy region in the spectrum, Shiut et al. (2010): Yonnis et al. (2009). The peaks at $2850.41 \mathrm{~cm}^{-1}$ and $2924.32 \mathrm{~cm}^{-1}$ indicate symmetric and asymmetric stretching vibrations of $\mathrm{C}-\mathrm{H}$ alkane groups respectively. They could be methyl $\left(\mathrm{CH}_{3}\right)$ or methylene groups in the esters chains of the biodiesel and they require high energy to cause stretching vibrations within their bond when compared to the ordinary $\mathrm{C}-\mathrm{H}$ bending vibrations of alkene groups detected at low energy and frequency region, Shiut et al. (2010). The characteristics peak at wavenumber $1745.89 \mathrm{~cm}^{-1}$ which is strongest in the spectrum is attributed to $\mathrm{C}=\mathrm{O}$ groups with the stretching mode of vibration. These groups indicate the presence of carbonyl functional groups in the biodiesel. The groups indicate the conversion of triglycerides in the oil to methyl esters, John (2000). The band region of $1376.00-1459.40 \mathrm{~cm}^{-1}$ can be ascribed to the bending vibration of $\mathrm{C}-\mathrm{H}$ methyl groups in the fuel, while the band at $1646.42 \mathrm{~cm}^{-1}$ is ascribed to $\mathrm{C}=\mathrm{C}$ bending vibrations in the biodiesel, Shiut et al. (2010). The characteristics peaks found in the region $1036.81-1248.60 \mathrm{~cm}^{-1}$ indicate stretching vibrations of C-O and C-O-C. They can also indicate the bending vibration of $\mathrm{O}-\mathrm{CH}_{3}$ in the spectrum, John (2000).

Table 2: Biodiesel Quality Parameters

\begin{tabular}{ccc}
\hline Parameters & Biodiesel & Biodiesel ASTM D6751 \\
\hline Pour point & -3.00 & $-3-16$ \\
Cloud point & 6.00 & $-3-12$ \\
Flash Point & 173 & $130 \mathrm{~min}$. \\
$\%$ yield & 81.25 & ------- \\
Density & 0.83 & ------- \\
Viscosity at 40 ${ }^{0} \mathrm{C}(\mathrm{cSt})$ & 4.37 & $1.9-6.0$ \\
Colour & Light Yellow & ------- \\
\hline \hline
\end{tabular}


Table 2 shows the quality of the synthesized biodiesel. From the table, it can be seen that the Pour point, cloud point, density and the viscosity Khaya senegalensis biodiesel falls within ASTM D6751standard for biodiesel specification, only flash point falls outside the standard. However, the density, viscosity and pour are higher than that reported by Danbature et al, while cloud point, and flash point are lower than those reported by same Danbature et al, (2015). The viscosity, cloud point, and pour point of the biodiesel falls within the ASTM D6751 standards (Table 2). However, the flash point Khaya senegalensis (Table 2) within the standards and is lower than those of sunflower, rape seed olive Jatropha curcas methyl esters (Table 2). Consequently, Khaya senegalensis biodiesel can ignite at a higher temperature than those of the other oils.

\subsection{CONCLUSION}

Transesterification of Khaya senegalensis performed by heterogeneous catalyst and methanol. The oil and biodiesel were characterized following ASTM standards. The biodiesel produced contained an ester functional group and revealed that it can be used as an alternative for fossil diesel in diesel engines.

\section{COMPETING INTERESTS}

Authors have declared that no competing interests exist.

\section{REFERENCES}

[1] S. Antony Raja, D.S Robinson Smart and C. Lindon Robert Lee, "Biodiesel Production from Jatropha oil and its Characterization" Res. J. Chem. Sci. 1(1): 81-87. 2011.

[2] AOAC. "Associaion of official Analytical Chemist, Arlington" Official Methods of Anlysis, 14 $4^{\text {th }}$ edition Vol. 67.1990.

[3] AOAC Official Method of Anlysis of the Associaion of Official Anlytical Chemist, Official Methods of Anlysis. Gaithersburg, USA. $16^{\text {th }}$ Edn. 1998.

[4] A. Demirbas "Biodiesel production from vegetable oils via catalytic and noncatalytic supercritical methanol transesterification methods" Progr Energ Combust Sci. 31:466-87. 2005.

[5] A. Demirbas "Biodiesel from sunflower oil in supercritical methanol with calcium oxide. Energy Conversion Management" 48 937941. 2007.

[6] A. Demirbas "Biodiesel: a realistic fuel alternative for diesel engines. Springer Verlag" 2005.

[7] A. Demirbas "Biodiesel from waste cooking oil via base-catalytic and supercritical methanol transesterification. Energy Conversion and Management" 50: 923-927. 2009.

[8] F. Edeh, and J. M. Yelwa "Production of Biodeisel by Transesterification of Waste Cooking Oil Using Prepared Heterogeneous Catalysts" Asian Journal of Applied Science and Technology (AJAST). Volume 3, Issue 2, Pp 57-64. 2019.

[9] J. Kansedo and K. T. Lee "Process optimization and kinetic study for biodiesel Production from non-edible sea mango (carbera odollam) oil using response surface methodology. Chemical Engineering Journal. 214:157-164. 2013.

[10] C. John "Interpretation of infrared spectra, a practical approach. Encyclopedia of analytical chemistry, R.A. Mayers (Ed). John Wiley and Sons Ltd, Chichester" 10815-10837. 2000.

[11] I.I. Nkafamiya, S.A. Oseheahon, D. Dahiru, and H.A. Umaru "Studies on the chemical compression and Physicochemical properties of the Seeds of baobab (Adansonia digitata)" African Journal of Biotechnology, 6(6)756-759. 2007.

[12] F.E. Okieimen and C.O. Eromosele "Fatty Acid Composition of the Seed oil of Khaya Senegalensis" Bioresource Technology, 69:279280. 1999.

[13] SH. Shuit, KT. Lee, AH. Kamaruddin, S. Yusup "Reactive extraction of Jatropha curcas seed for production of biodiesel" Process optimization study. Environ. Sci. Technol. 44. Pp 4361-4367. 2010.

[14] P. Rezende, T. F. Silva, R. C. Castro, E. V. R. and I. C. P. Forte "Multivariate calibration by variable selection for blends of raw soybean oil/biodiesel from different sources using Fourier Transform Infrared spectroscopy (FTIR) spectra data," Energy Fuels, vol. 22, pp. 2079-2083. 2008.

[15] Y.H. Taufiq-Yap H.V. Lee M.Z. Haussein, and R. Yunus. "Calcium base-catalyzed Transestrification of jatropha curcas oil to biodiesel" Human and Bioenergy. 2010

[16] V.B Veljkovic, SH. Lakicevic, O.S. Stamenkovic, Z.B. Todorovic, and M.L Lazic "Biodiesel production from tobacco (Nicotiana tabacum L.) seed oil with a high content of free fatty acids" Fuel. 85: 2671-2675. 2006.

[17] J.M. Yelwa, S.A Osemeahon, I.I Nkafamiya, and S. Abdullahi "Synthesis and Characterization of Hydroxylated 
Sunflower Seed Oil/ Poly Vinyl Acetate Copolymer s Binder For Possible Application in the Coating Industry" International Journal of Innovative Research and Advanced Studies (IJIRAS) Volume 4 Issue. Pp 417-418. August, 2018.

[18] MN. Yonnis, MS. Saeed, S. Khan, MU. Furqan, R.U Khan, M. Saleem "Production and characterization of Biodiesel from waste and vegetable Oils" Journal of Quality and Technology Management. 1(1):111-121. 2009. 